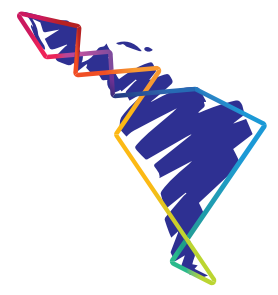

\title{
"Afortunadamente": Historia oral de una familia salvadoreña y su migración Norte-Sur
}

\author{
"Fortunately": Oral history of a \\ Salvadoran family and their \\ North-South migration
}

\section{"Felizmente": História oral de uma família salvadorenha e sua migração Norte-Sul}

\section{Maité Cristina L. López’}

\begin{abstract}
Resumen
El objetivo de este ensayo es acompañar, por medio del testimonio, tradición oral latinoamericana, a nuestra coescritora salvadoreña en su camino de migración del Salvador a Costa Rica. Abrirnos a la riqueza vivencial que surge de las palabras y memorias como espejo de nuestras realidades centroamericanas y costarricenses. Desde la voz de nuestra colaboradora, se asoma un Centroamérica con una historia de imposición colonial, imperialista y capitalista que siembra, sobre nuestras ricas tierras, una cultura de violencia penetrante, desde los vientres de las mujeres hasta los Estados nacionales, cuyos frutos son la necropolítica, la xenofobia y la pobreza sociocultural y económica de nuestros pueblos.
\end{abstract}

Palabras clave: Migración, Centroamérica, necropolítica, xenofobia, comunidades, testimonio.

1 Actualmente cursa la Maestría en Estudios Latinoamericanos del IDELA, Universidad Nacional, Costa Rica. Licenciada en Humanidades, graduada con honores y máxima distinción en Sociología, con especialidades en Derechos Humanos y Sociología, sub-especialidades en Periodismo y Estudios de la Mujer y el Género de la Universidad de Saint Thomas en Fredericton, New Brunswick, Canadá. Investigadora enfocada en el trabajo sexual en América Latina. Correo electrónico: maitecristina@live.ca. ORCID: https://orcid. org/0000-0001-6553-7018. 


\begin{abstract}
The objective of this essay is to accompany, through testimony, oral tradition of Latin American, our Salvadoran co-writer on her migration journey from El Salvador to Costa Rica. To open ourselves to the experiential richness that emerges from words and memories as a mirror of our Central American and Costa Rican realities. From the voice of our collaborator, a Central America appears with a history of colonial, imperialist and capitalist imposition that sows, on our rich lands, a culture of pervasive violence, from the wombs of women to the nation States, whose birthed fruits are necropolitics, xenophobia and sociocultural and economic poverty of our peoples.
\end{abstract}

Keywords: Migration; Central America; Necropolitics; Xenophobia; Communities; Testimony.

\title{
Resumo
}

O objetivo deste ensaio é acompanhar, por meio do testemunho, a tradição oral da América Latina, nossa coautora salvadorenha em sua trajetória de migração de Salvador para a Costa Rica. Abrimos para a riqueza experiencial que emerge das palavras e memórias como um espelho das nossas realidades da América Central e da Costa Rica. Da voz de nossa colaboradora, surge uma América Central com uma história de imposição colonial, imperialista e capitalista que semeia, em nossas ricas terras, uma cultura de violência generalizada, desde os ventres das mulheres até os estados Nacionais, cujos frutos são a necropolítica, a xenofóbica e a pobreza sociocultural e econômica de nossos povos.

Palavras-chave: Migração; América Central; Necropolítica; Xenofobia; Comunidades; Testemunho.

Vivimos una guerra regional no declarada; una diáspora centroamericana forzada, cruel y criminalizada. Desde los márgenes de nuestras imaginadas naciones centroamericanas, las mujeres y sus familias recogen sus pertenencias personales, lo que aguante el hombro, y prenden camino a otras direcciones en busca de seguridad, esperanza y prosperidad. Los núcleos comunales y de familias extensas son cruzados y separados por los ríos sangrientos del crimen organizado; las maras; los gobiernos represores y autoritarios; los gobiernos que han perdido sus Estados de derecho; el capitalismo, imperialista y destructor de nuestras tierras, nuestras cosmovisiones, nuestro derecho a vivir o subsistir siquiera. El sueño capitalista, como el "americano", no son más que el mismo sueño y no tienen ya la capacidad de esconder su cruda realidad, el no existir, el ser una fábrica de movilización de poderes que buscan no más que engordar los bolsillos de algunos pocos, al costo de las masas humanas que habitan nuestro planeta.

Latinoamerica representa "la región más violenta del planeta, fuera de las zonas de guerra. Seis de cada 10 robos son cometidos con violencia y el noventa por ciento 
de los homicidios no son resueltos. Sus cárceles están entre las más hacinadas en el mundo" (Bachelet, 2017, párr. 3). Sin embargo, la violencia, la impunidad ante la injusticia, la pobreza institucionalizada, el desarraigo de las comunidades, la destrucción de nuestros territorios, la cosificación de personas y recursos naturales, y la criminalización de las comunidades son consecuencia de una herencia colonial que permitió que nuestras tierras, comunidades y culturas se doblegaran a las necesidades del imperio estadounidense. Desde la época colonial hasta el presente, estas tierras nunca han servido para el bien de nuestros pueblos. Rita Segato (2018) nos habla sobre la visita de generales retirados estadounidenses a diferentes países de América Latina ofreciendo asesorías para el control de pandillas, donde los presidentes de cada país se preguntaban sobre cuáles pandillas hablaban los retirados:

Tres años después los tiene que llamar y dan su clase en la Escuela Superior de Guerra. Yo sí pienso con la teoría del complot, no me asusta. Creo que lo que pasó en nuestros países es la prueba cabal de la existencia de un complot, porque es tan parecido en países tan diferentes entre sí. La misma embajadora norteamericana estaba en Honduras, Paraguay y Brasil: y en los tres hubo golpes. Sícreo que hay una conspiración contra nosotros, por el control del territorio de los países de América Latina. (Segato, 2018, párr. 18)

El complot contra nuestra América es la necesidad de controlar nuestros territorios para cumplir con la agenda hegemónica estadounidense y asegurar su posición dominante en el mundo. Sin embargo, no es una realidad de las últimas décadas; al contrario, la intervención estadounidense en nuestra América es histórica (Elbaum, 2018). La Guerra Fría y la Agencia Central de Inteligencia (CIA) estadounidense se encargaron de imponer y establecer dictaduras con el discurso de la guerra contra el comunismo y el autoritarismo, en nombre de la democracia y del progreso. Estas dictaduras y sus constantes violaciones de derechos humanos dejaron una Centroamérica con tejidos sociales, políticos, culturales y económicos quebrantados.

Se puede afirmar que las torturas y el homicidio, las violaciones y desapariciones generaron en la mente y el corazón de las personas víctimas de la guerra una manera diferente de estar en el mundo, caracterizada por el descontento, el dolor y el sufrimiento como formas de ver y explicar la vida: la cultura de la violencia. (Cuevas, 2012, pp. 173, citando a Chéster Urbina)

La cultura de la violencia se permea y reproduce la inseguridad y desconfianza; además de provocar la necesidad de migrar a otros espacios, para escapar de la violencia, el genocidio, el hambre y el miedo. 
Las caravanas de migrantes provenientes de Honduras y El Salvador se acercan a la frontera de Estados Unidos. Huyen de la violencia, el hambre y la desocupación provocados por un modelo socioeconómico instaurado por Washington, a partir de su complicidad con las familias terratenientes de los países centroamericanos. (Elbaum, 2018, párr. 1)

Estos mismos jóvenes que migraron a EEUU se encontraron en un país racista, xenofóbico y segregado. En esta realidad, convirtiéndose en una población entre ilegal y discriminada, se crean las primeras pandillas californianas entre latinos. Estas pandillas se gestionan basadas en las necesidades de sus miembros, con bajos niveles de educación, y una socialización de terror y violencia histórica generada por las dictaduras; además, justificadas en la óptima necesidad de acceder a la movilidad social y al mercado capitalista. En los márgenes de la sociedad estadounidense, las pandillas encuentran oportunidades en las orillas del mercado, las drogas, los robos, la violencia (Cuevas, 2012).

Al finalizar la Guerra Fría, EEUU busca la forma de mantener su poderío formulando su política y represión contra Latinoamérica, cerrando fronteras, criminalizando poblaciones latinas, ejecutando deportaciones masivas dentro de su territorio e impulsando la infame "guerra contra las drogas" y la doctrina de seguridad para América Latina. México, doblegado bajo su poder a servir de capataz contra sus propias gentes, árbitro comprado y parcial a las realidades históricas y modernas de nuestra región. Miles de pandilleros latinos son apresados y luego deportados de vuelta a sus países, convertidos en criminales (Cuevas, 201). Es aquí donde las maras comienzan a aparecer y a empoderarse de Centroamérica, junto con el crecimiento del crimen organizado y la desaparición completa de los Estados de derecho. Esta "segunda realidad o estado" como le llama Segato (2018), perpetúa el continuo desmantelamiento de cualquier esfuerzo latinoamericano de autogestionarse para proteger los derechos de sus pueblos, tierras e instituciones.

La debilidad del Estado es una condición de inseguridad que lo afecta a él mismo, como a su población. Y va más allá. La inseguridad en un Estado genera una expansión de ésta a los vecinos. La inseguridad fluye más allá de las fronteras. (Rojas, 2008, pp. 8)

contemporánea, el propósito de este ensayo es visualizar, por medio de la historia oral, los siguientes ejes temáticos:

1) Cultura de la violencia centroamericana que reproduce la migración forzada.

2) Desafíos de la persona migrante al buscar refugio en Costa Rica.

3) Beneficios de la interculturalidad en las comunidades. 
Estos ejes temáticos tienen, como objetivos, visibilizar las realidades centroamericanas y desmentir los mitos migratorios que promueven y reproducen la xenofobia y la violencia al otro ser; reconocer el déficit estatal e institucional del manejo adecuado de poblaciones migratorias, lo que tiene como consecuencia un déficit educacional de sensibilización social con la sociedad entera y sus funcionarios públicos y, finalmente, reivindicar el potencial humano, social y comunal de las poblaciones migrantes, no como una carga social sino como un agregado esencial, con un legado experiencial y una sensibilización comunal de valor incalculable para nuestra sociedad costarricense contemporánea.

El Salvador, como parte del triángulo norte, se encuentra entre los países con mayores indices de violencia del continente (Bachelet, 2017; Cuevas, 2012; Dalby y Carranza, 2019; Rojas, 2008; Valencia, 2018). Las mara Salvatrucha y Barrio Dieciocho se pelean por territorios violando, matando y destruyendo todo lo que se cruce en su camino (Dalby y Carranza, 2019; Poveda, 2009). Quienes viven al margen de la impunidad gubernamental, la corrupción y la guerra territorial marera (Barrios, 2016) son las primeras víctimas de la violencia, la coerción, el miedo y la necro-política centroamericana; dentro de estas realidades, la migración se formula como una acción de sobrevivencia y, por ende, como un derecho humano.

Yo soy originalmente del Salvador. Vivimos allá con mi esposo y mi hija, que para el 2011, que fue cuando migramos para acá, era una bebé, tenía once meses. Fue como una sucesión de eventos, ¿no?

Sucedió que, en julio del año anterior, o sea 2010, el hermano de mi esposo fue asesinado por las maras. Él tenía un camión y hacía transportes de gente y de materiales. Circulaba por muchos lugares en la ciudad, y empezó a ser extorsionado, y, después de mucho tiempo de estar pagando extorsiones, lo citaron, porque el problema de las maras en El Salvador es como bastante serio, ¿no? Y a veces hay como, como una tendencia a querer dar el ejemplo a otros, por decir así. Entonces lo citaron, y, lo asesinaron, le dieron unos... tres balazos en la cabeza.

Este... eh... bueno a mi esposo le avisaron, inmediatamente él fue hasta donde estaba el lugar donde lo habían asesinado, y... resulta que sus mismos asesinos estaban ahí cuando estaban haciendo el levantamiento policial, luego... en el funeral estaban ahí también, es decir, pues, que reconocieron a toda la familia de él, ¿no? Entonces como esa fuente de ingreso se (les) acabó, había que buscar otra, y como que la familia era la lógica más cercana y como ya estaba la experiencia de que no importa cuánto dinero vos des, eso no te asegura la vida, ¿verdad? No te asegura que... van a respetar tu integridad física. 
Nosotros teníamos, tenemos una hija, nuestra hija en ese tiempo era una bebé, entonces, así como que, sin pensarlo, sin pensarlo mucho, sin mucha planificación en diciembre de ese mismo año decidimos emigrar a Costa Rica. (Comunicación personal, Álvarez, 2019)2

Quiero que sepas, cuanto es que pasa, cuanto es que duele ver caerse mi ciudad, también decirte que también pierdo la cabeza y no pienso en nada más,

quiero contarte,

la dura historia de lo que pasa cuando vas de norte a sur, cuando en el bosque salen los lobos

y como un niño herido queda el alma en soledad, talvez dormía! talvez robaba!

talvez cansado de su barrio marginal, también nos dijo que también muere, en el intento de encontrarse en libertad, cruza fronteras de norte a sur cruza fronteras de norte a sur cruza fronteras de norte a sur. (Perrozompopo, Quiero que sepas)

En un mundo donde las políticas exteriores obligan a nuestros gobiernos a aplicar leyes de mano dura contra sus poblaciones y a cerrar fronteras, los testimonios de inmigrantes nos ofrecen un espacio de sensibilización y de integración entre comunidades de diferentes regiones, pero con necesidades humanas iguales.

Cada relato personal es un fragmento de una historia social de la que todo sujeto es parte esencial y complementaria, la historia oral -como aproximación a los procesos migratoriosofrece elementos que se vuelven clave para entender desde una sola historia, el devenir del mundo en muy diversos temas que pueden rebasar, con mucho, al proceso migratorio mismo, como son las consecuencias globales de la demografía, la ecología, los sistemas políticos, la violencia, la desigualdad. (Calderón, 2017, pp. 272)

Como un país altamente xenofóbico y cuyo mismo Estado está bajo la presión de doblegar su poderío ante el imperialismo, la represión policíaca y el crimen

2 Este texto se basa en su plenitud en la entrevista a profundidad realizada en el año 2019 a una mujer salvadoreña con estatus de refugiada en Costa Rica. 
organizado, Costa Rica puede no sólo aprender muchísimo sobre las realidades de las poblaciones vecinas, sino también sobre los beneficios de la entrada de migrantes al país y la potencialidad que crece de la colaboración, el resguardo de derechos y la autosuficiencia. La migrante salvadoreña que comparte su historia en este texto, con el deseo de plasmar sobre esta hoja el historial escrito, para que se una a otros, se convierte en nuestra colaboradora. No sólo a nivel académico, sino también como vecina que se integra, comparte y mejora el mismo territorio del cual el pueblo costarricense clama derechos sólo por haber nacido en él. El recorrido de su familia no estaba falto de cansancio y angustia, pero sí de afortunadas conexiones con aliados en los diferentes países de tránsito.

Afortunadamente, hay unas personas con las que mi esposo trabajó en El Salvador, es una pareja, ella es de Argentina y él de Estados Unidos, que yo conocía y que ahora están asentadas aquí, y ha sido como la comunidad que nos ha acogido, ¿no? Que nos ha acogido desde que llegamos. En un primer momento, nos proveyeron prácticamente todo: casa, comida, apoyo emocional, familia, amistad, y con el devenir del tiempo, pues, ya fuimos encontrando más estabilidad, aunque todavía no estamos 100\% estables, pero si fueron como una parte importante de ese proceso de migración.

Primero mi esposo se vino como para ver cómo era la cosa, ¿verdad? Para ver si era un lugar seguro para que pudiéramos estar los tres y etc. Él se vino como un mes antes de nosotros, después llegamos nosotros. Y bueno hasta el día de hoy estamos en la misma casa donde llegamos porque aqui encontramos la comunidad. Vinimos por tierra los tres, como te digo T. se vino primero él, y se vino transbordando, o sea, haciendo paradas, bueno afortunadamente también él conoce gente en varios países entonces siempre encontró quien lo acogiera para salir en Honduras, quien lo acogiera en Nicaragua, quien lo acogiera aquí, y hasta llegar a Costa Rica, ¿no? Y luego mi hija y yo sí nos vinimos ya directo en Tica Bus, un viaje de veinte, veintitrés horas con una bebé en un bus pero... sí. (Comunicación personal, Álvarez, 2019)

Es difícil no notar la unión entre migrantes que existe dentro del país. Aquellas personas que han vivido situaciones similares comprenden, por experiencia propia, las dificultades que surgen de estos procesos migratorios. El reto que tenemos en Costa Rica es cómo inculcar esta solidaridad y combatir la xenofobia que radica en la ignorancia y el rechazo irracional al otro sujeto. Cómo aprender de los desmantelamientos sociales de nuestras naciones centroamericanas e incentivar la lucha por derechos en Costa Rica, empezando por una revolución educativa que nos sensibilice y empodere a ser una ciudadanía activa y comprometida con las poblaciones que no sólo radican dentro de la frontera política costarricense, sino también con aquellas que buscan refugio y prosperidad aquí. 
En enero (2011) iniciamos el proceso de solicitud de refugio en las oficinas de migración. En realidad, nosotros cuando llegamos ni siquiera sabíamos que esa era como una opción a la que podíamos aplicar, iverdad? Si no que a través de conversaciones y de gente entonces como que nos orientaron que lo debíamos hacer, entonces empezamos ese proceso de solicitud de refugio.

Y bueno afortunadamente, antes de salir una amiga nuestra en El Salvador, que es abogada, que estuvo muy cerca de toda esta situación nos dio muy buenos consejos como: "lleven sus partidas de nacimiento apostilladas, lleven sus documentos de títulos apostillados," o sea, eso fue una cosa que nos facilitó mucho iniciar el proceso, porque generalmente en situaciones de refugio principalmente es lo menos que piensas, ¿verdad? Salís huyendo y tener tus documentos al día, es como una cosa que muy pocas personas hacen y todos los documentos que te piden en migración deben estar apostillados porque si no, no son válidos, ¿verdad? Entonces esa fue una cuestión que nos ayudó mucho a tener un proceso un poco más, no sería acelerado, sino más amigable, porque no es que por eso hayamos hecho las cosas más rápido, si no que mas amigable y menos conflictivo, porque a partir de todas estas experiencias nosotros hemos estado muy cerca de otras familias que también han tenido que salir de sus países por condiciones de violencia y solicitado refugio, y realmente es una traba en el proceso no tener tus documentos al día.

Un año y medio después de haber llegado nos otorgaron el refugio y a formalmente porque eso es todo un proceso, ¿verdad? Como en mayo del 2012 fue que nos dieron el refugio.

Muchas personas piensan que vos llegas y solicitas refugio y ya estuvo, ya te lo dieron y eso no es así. Si no que hay entrevistas, hay que presentar documentación. En esta época, la oficina de migración tiene una deuda grande, porque obviamente las migraciones en los últimos años, a partir de muchos problemas sociales en los diferentes países... pero hoy en día se están dando alrededor de dos años para una resolución entonces se ha vuelto un poco más complicado, un poco más terrible con este proceso de refugio.

En teoría también, bueno en nuestro caso si fue cierto que tres meses después nos dieron un permiso de trabajo, iverdad? para que pudiéramos laborar en el país, en abril, mayo del 2011, nos dieron esto que es como un carnet que le dan a uno para probar que tiene un proceso abierto y que tienes una instancia legal en el país.

Sin embargo, esto tampoco asegura que uno vaya a obtener un trabajo, ¿verdad? En primer lugar, porque muchas de las empresas ni siquiera reconocen como válido ese documento hay desinformación, aunque es un documento legal y válido, hay gente que no lo conoce, o sea se lo muestras y dicen: "iy esto qué es? Esto no es una cédula, esto no es, esto es..." o quizás ha mejorado un poco porque hay muchas ONG que han estado haciendo procesos de sensibilización en el tema de empleabilidad, sin embargo, 
cuando nosotros llegamos no era así, aunque teníamos ese documento, no fue una cosa fácil encontrar trabajo.

Esa es una cuestión bastante difícil, principalmente porque las personas funcionarias de las instituciones... no sé si es que no están al tanto de la información o si la información se queda en los niveles altos y no llega hasta la persona que atiende, pero este... sí... sí es... como te digo es como que llegues con el documento y te digan, "iy esto qué es?" o sea, desconocer completamente que hay un documento legal, ¿verdad? Que la dirección de migración te extiende y que tiene completa validez. En el caso, bueno, nosotros no sabíamos, por ejemplo, que los niños tenían la atención asegurada hasta los dieciocho años, si no porque alguien nos contó, ¿verdad? No es una información que, por ejemplo, te den en la oficina de migración o estas ONG que atienden, que en ese momento solamente era una, era ACAI nada más, la que atendía refugiados. Entonces, cuando te ven que llegas con una niña pequeña y que muy posiblemente ni siquiera tiene completo su sistema de vacunación porque es una bebé, o sea, y siento yo que son como informaciones básicas que deberían de darte, ¿no?

Y también todo un sesgo de género que se ve. Porque cuando hubo una ocasión, en que mi esposo llevó a mi hija al Ebais, a la clínica, y no sé yo por qué yo no fui con ella, y tuvo que ir a validación de derechos, ¿verdad? Y lo primero, "iiy usted por qué no trabaja para pagarle el seguro a su hija?!” O sea... así... cuando tienes unos meses de llegado, cuando... estás tratando de reencontrarse, cuando... bueno, no necesariamente ella tiene que saber toda la historia, ¿verdad? Pero pienso que no son maneras de tratar a la gente. (Comunicación personal, Álvarez, 2019)

La situación crítica en la que está sumergida Centroamérica requiere que nuestros gobiernos gestionen las realidades para nuestras comunidades, y no para garantizar o reproducir los ideales y las políticas institucionalmente hegemónicas y de supremacía blanca de EEUU.

La seguridad es interdependiente. Ello requiere un abordaje comprensivo que dé cuenta de manera simultánea de diferentes políticas públicas tales como las referidas a: reformas de los sistemas de seguridad y defensa; reformulación de las politicas sociales; el desarrollo de políticas que contribuyan a la cohesión e integración social; y un conjunto de iniciativas que permitan mejorar la gobernabilidad democrática. (Rojas, 2008, pp. 5)

Es prioritaria la educación de las personas funcionarias de instituciones del país, de los diferentes y diversos sectores, en el reconocimiento de documentos de identificación y en los derechos de esta población migrante, es necesario romper con leyes que promuevan la exclusión y formular la obligación legal, social y humana de incluir al otro ser ilegal, migrante, refugiado, mujer, indígena, persona de la 
comunidad LGTBQI, el otro no ser humano blanqueado. Se necesitan leyes que promuevan la generación de empleos y una cultura de trabajo y educación continua, de manera que no sigamos viviendo bajo el imperialismo neoextractivista de nuestra época. Es importante que las personas que constituyen el otro sujeto tengan la oportunidad de laborar para subsistir. Y más importante aún, que el funcionariado no se atribuya el derecho de decidir quién tiene derecho a trabajar y quién no. Este testimonio nos permite ver la realidad costarricense y visualizar las debilidades del sistema legislativo y cultural. No sólo alimenta la realidad migrante, sino también la realidad que viven los otros grupos sociales que habitan en el país. No es la diversidad de grupos la que causa conflicto: es la incapacidad del gobierno de responder a estas poblaciones diversas responsablemente y de acuerdo con los derechos y discursos democráticos, que sí se proclaman en tiempos electorales.

Tanto mi esposo como yo teníamos estudios universitarios también, ¿verdad? Yo estudié terapia física en El Salvador y él es ingeniero en sistemas, pero los títulos universitarios de otro país hay que validarlos aquí y esto es un proceso también un poco tedioso y caro, o sea, si no tienes los medios económicos para hacerlos, si no trajiste toda la documentación que necesitas de tu país es un proceso que no se puede hacer. Entonces fue como bastante difícil en ese proceso de encontrar empleo a pesar de que bueno uno dice: "estudié, y eso no quiere decir que..." o ¿cómo lo plantearía mejor? Que uno cuando va a la universidad saca un título y espera no tener que ir a trabajos precarios, pero nos tocó, nos tocó hacer jardinería, nos tocó limpiar casas, nos tocó vender comida, nos tocó hacer esas labores que se supone no tendríamos que hacer en nuestro imaginario, ¿verdad? Pero en la realidad si tuvimos que enfrentarnos a eso.

Bueno eso fue una etapa bastante difícil también porque tenía una bebé, ¿verdad? Que acababa de cumplir un año, entonces cuando uno está en esta situación y encima no tienes una comunidad alrededor, o una red de apoyo alrededor que te ayuda con la crianza de los niños y niñas se vuelve una cuestión bastante difícil. De hecho, yo creo que, aunque no diagnosticada yo tenía un mi proceso de depresión en este primer año. Donde realmente hubo deseos de regresar, a pesar de saber que no había una seguridad ni para mí, ni para mi familia. Pero uno se ve despojado de tanta, de toda la red de apoyo de, incluso, el mismo hecho de no poder desplazarse libremente porque no conoces el entorno, no sabes qué bus tomar para ir a equis lugar, no sabes por qué calles caminar, por qué calles no caminar, y eso unido a todo el proceso traumático, iverdad? De la muerte de un familiar, de forma violenta, del ser arrancada de tu lugar, el desarraigo...

Entonces bueno, el primer año fue bastante difícil, luego el segundo año, a través de amistades conseguí un trabajo a medio tiempo como recepcionista en una academia de baile, que también era como... "todavía no hemos llegado", ¿verdad? Pero estando ahí, ya con un poco más de ingreso, empecé a estudiar inglés en la UCR y ya estando como 
en ese mundo universitario, bueno dije: "yo aquí con mi carrera, yo no voy a hacer mucho," entonces decidí ese año inscribirme para el examen de admisión de la universidad, eso fue en el 2013. Después de 20 años de no hacer nada de razonamiento lógico, ni matemáticas, ni nada por el estilo, y sin posibilidades tampoco de decir: "bueno, voy a pagarme un curso", porque no había mucha plata. Entonces empecé a estudiar yo sola para el examen de admisión, hice el de la UCR y el de la UNA, y en ambos califiqué. Pero ya por razones de distancia, porque como vivo en Santo Domingo, de tener una hija, entonces me quedé en la UNA. Y por razones también ya propiamente de realidades, escogí la carrera de Género y Desarrollo... que justamente ahora estoy ya en el último semestre, ya, como en el proceso de mi tesis.

Esa es la otra parte de la historia, o sea yo quise entrar en la maestría en Derechos Humanos, ¿verdad? Y como ya tenía una carrera universitaria en El Salvador, entonces yo intenté con ese título entrar. Pero no me lo valieron, no me lo aceptaron, porque no estaba convalidado, entonces, esa es otra limitante, ¿verdad? O sea, digamos que tu título no te sirve en absolutamente para nada. Entonces como en el 2018 yo me gradué del bachillerato en Género y Desarrollo, entonces (wooala) allá voy, ya con eso, ya la cosa cambió, y ahora sí me aceptaron la aplicación y todo, y ahorita estoy haciendo el primer semestre. Y para no esperar dos años más, entonces decidí sacar la maestría al mismo tiempo. (Comunicación personal, Álvarez, 2019)

La migración forzada, como podemos ver, no sólo expone a la persona migrante a un desarraigo inmediato e indeseado; también le obliga a descender la escalera que permite su movilidad social en nuestras sociedades. Sus cualidades, estudios y experiencias quedan en ese otro mundo imaginado, otra realidad de vida, otra visión de futuro. Llegan a otro país que no está equipado o interesado en gestionar su bienestar. Este es el otro lado de la moneda de los sujetos expatriados norteamericanos que residen en nuestro país, donde sus pensiones les permiten vivir una vida digna en un país hermoso, con un sistema de salud universal; contrariamente, esta misma pensión los mantendría en la pobreza en sus países de nacimiento, a esto se le llama, movilización social transnacional (Hayes, 2018), y demuestra la desigualdad social Norte-Sur. Este tipo de investigaciones deben iluminarse en los mundos académicos y sociales.

Y sí, o sea, hay mucho sesgo en cuanto al migrante y dependiendo de donde vengas, como te digo, aquí en Costa Rica los salvadoreños no somos muchos todavía, entonces, no siento yo que no hay un, no hay... tantos sentimientos negativos como los hay hacia la población nicaragüense, por ejemplo, iverdad? Pero, bueno, si ya te encuentras con un venezolano, entonces el trato ya es mucho mejor, porque se supone que ellos ya tienen mayor nivel educativo, porque se supone que ellos traen, bueno y cierto, algunos de ellos trajeron plata para hacer negocios, pero no todos, entonces sí, o sea hay clasificaciones 
entre, dependiendo de donde vengas ese es el trato que mereces, ¿verdad? Bueno otra cosa que no sé si es buena o mala es que muy difícilmente nos identifican el acento, o sea, la gente sabe que no somos de aquí, pero no saben de donde somos. Entonces eso de repente se convierte en una ventaja, porque ya no te estigmatizan con solo el hecho de empezar a hablar, que pasa, pasa, ¿verdad? (Comunicación personal, Álvarez, 2019)

Mirando al sur encuentro más fronteras,

Encuentro calles antes recorridas,

Encuentro gente que camina sobre el río,

Gente que camina en el camino.

Mirando al sur encuentro más senderos,

Momentos y recuerdos de otras vidas,

Papeles no firmados, la foto de los hijos, Encuentro la frontera que viví de otra frontera.

Mirando al sur encuentro mi otra parte,

Mi otro igual, un paralelo, un semejante, Encuentro que hay más vida, no importa donde mires, No importa que tu boca sea igual que cualquier boca.

El mundo es la mezcla

De todos los pueblos,

De todos los dioses,

De todas las lenguas.

El mundo es la mezcla

De tantos caminos,

De varios colores,

Que mezclan sus lenguas.

Mirando al sur encuentro más familias

Que miran hacia el sur desde otra parte,

Me encuentro a otro igual, a un paralelo, a un semejante

$Y$ encuentro que mi boca besa igual que cualquier boca.

(Perrozompopo, Mirando Al Sur)

¿Por qué nos molesta que los grupos latinos utilicen los sistemas de salud, educación y transporte público de nuestro país, pero tan amablemente les abrimos la puerta a estadounidenses y canadienses? ¿Por qué no facilitamos y nos equipamos para asegurar que profesionales que lleguen al país puedan ejercer su profesión y fortalecer nuestra sociedad profesional, pero sí les permitimos a sujetos migrantes blancos pensionados construir acá sus comunidades cerradas, aunque dentro del marco capitalista, estas personas pensionadas no contribuyen a nuestra economía? ¿Por qué el individuo blanco camina como perro por su casa, pero el latino se arrastra en las tinieblas de la inseguridad? ¿Qué dice eso de nuestra cultura y 
mentalidad colonizada? ¿Cómo creamos y defendemos una América Latina para población latinoamericana, si el bienestar que nos preocupa y que aseguramos no es nuestro, pero sí del Norte blanco? ¿Cómo nos de-construimos como sociedad para re-aprender lo que sí nos representa? ¿Cómo definimos qué es lo que sí nos representa? Lo que queda claro es que tenemos un largo y difícil camino por delante y una fuerza imperialista que está haciendo todo lo posible por evitar nuestra verdadera emancipación. ¿Qué tipo de iniciativas podemos fomentar para la reivindicación de nuestras tierras?

Y bueno con el ámbito laboral, como mi carrera de Desarrollo está orientada al trabajo comunitario, a los proyectos, entonces con esta misma pareja, que nos han acogido en su casa, decidimos formar una asociación. Y estamos trabajando, mi esposo y yo, ahora en Casa Adobe, de la cual somos fundadores y en la cual estamos orientados (en) pequeños proyectos de desarrollo comunitario y que gestamos sobre todo a dar oportunidad a la gente que no las tiene ${ }^{3}$, iverdad?

Uno de nuestros enfoques ha sido precisamente trabajar con personas refugiadas, porque hemos visto en carne propia, qué significa ser refugiado en un país. Ahorita precisamente estamos acompañando a una familia venezolana que vino en agosto del año pasado y que está viviendo estos mismos procesos, y es importante recalcar que no es lo mismo ser migrante venezolano, que salvadoreño, que nicaragüense, que gringo o lo que sea. O sea, hay ciertos prejuicios depende de dónde vengas y dependiendo de eso así te van a tratar, iverdad? O así van a hacer las oportunidades que vas a obtener. Que eso lo hemos visto en nosotros como muy claramente.

Mi esposo también volvió a estudiar, hizo una maestría en Estudios Teológicos con una universidad de Canadá, que le dieron una beca, también gracias a estos amigos con los que estamos viviendo, hizo su tesis precisamente en este tema de los refugiados y las iglesias en el país, ¿cómo están respondiendo? ¿Verdad? También las iglesias ante esta problemática social, que en estos últimos años se ha presentado mal por diversas críticas, ¿sabes? Entonces, sí, así es.

3 "Un refugio de sueños y subversiones, personas y personalidades, amores y fracasos, deber y descanso, risas y pérdidas, misión y meditación, barro y alabanza, procesos y propósitos, comida y conversación, trabajo y reflexión, semillas y brotes de la nueva creación. Casa Adobe aspira a ser una comunidad en la que las personas que son diferentes aprendan a vivir como ciudadanos de Santa Rosa, cuidando la creación, construyendo relaciones verdaderas y alimentando su fe en un Dios de amor y justicia. Somos como ladrillos de adobe: hechos de arcilla, imperfectos, fuertes solo cuando un Maestro nos une y en necesidad de retoques constantes. Al mismo tiempo, juntos crecemos con la alegre esperanza de que es posible encarnar nuestros sueños y los suyos. Nuestro sueño se manifiesta en nuestras diversas prioridades e iniciativas que llevamos a cabo como comunidad" (Casa Adobe, Nuestro Sueño [itálica agregada]). 
Sí, bueno ese (huertas urbanas) es uno de nuestros ejes, como te digo, nuestro principal, o nuestro lema es ser buenos vecinos en la comunidad donde estamos y a partir de las relaciones con los otros grupos organizados de la comunidad: la Asociación de Desarrollo, asociaciones específicas, como de deportes, hemos visto diferentes necesidades en nuestro barrio. Si has oído hablar de Santa Rosa, sabrás que es la parte mala de Santo Domingo, así la conocen, o la parte pobre, y no es que sea mala ni es que sea pobre, si no que es simplemente que muchas veces no se dan las oportunidades que la gente joven necesita para salir adelante, ¿verdad? Aqui hay problemas grandes de drogas, tanto de consumo como de distribución. Los mismos problemas sociales, si queremos llamarlos de alguna manera, sobreexplotación laboral donde los padres y madres no tienen tiempo para dedicarle a sus hijos, o bajos niveles de escolaridad que no les permiten ayudarles a sus hijos hasta cierto nivel. Entonces empezamos como queriendo suplir esa necesidad, iverdad? Uno de nuestros primeros proyectos fue precisamente darle ese apoyo escolar a los niños y niñas del barrio con tutorías en las diferentes áreas que ellos necesitaran, como matemáticas, sociales, ciencias, que es simplemente venir y que el niño o la niña tengo un espacio donde sentarse, con quién sentarse y con quién hacer sus tareas y quién le explique si hay algunos temas que no entiende, iverdad?

Empezamos con eso, luego como a partir de la Asociación y de otros proyectos anteriores recibimos voluntarios del extranjero, principalmente de Estados Unidos, aunque ahora tuvimos una chica nicaragüense que fue una experiencia bastante interesante, tenemos ahora un muchacho de Canadá, tuvimos un tico también. Entonces, bueno, la comunidad dijo: "ustedes tienen potencial para enseñar inglés, o tienen... entonces bueno hagámoslo". Entonces tenemos varios espacios abiertos tanto para niños, como para adultos, en la enseñanza del inglés.

Y también como uno de nuestros ejes principales es el cuidado del medio ambiente, el cuidado de la creación, entonces también decidimos hacer una huerta comunitaria, tenemos un espacio en el salón comunal, y otro espacio aqui en las mismas instalaciones de Casa Adobe, entonces nada, las señoras vienen, siembran con nosotros, sacamos plantitas, almácigos, luego ellas se los llevan para su casa y los ponen en una maceta. O a veces sembramos en el terrenito este que nos ha cedido la Asociación de Desarrollo y luego nos repartimos los frutos. Ha sido una oportunidad primero de enseñarle a varias mujeres, sobre todo, porque siempre son las que se involucran más que los hombres por diferentes motivos, ¿cómo podemos generar un impacto positivo en el medio ambiente? ¿Cómo podemos generar menos basura a través de la elaboración del compost? ¿Cómo podemos usar materiales reciclados para sembrar nuestras plantas? Sí, eso es lo que hacemos, y bueno, y en este año precisamente, que hemos empezado un proceso de la recuperación de la relación de la comunidad con la parte del Río Virilla que nos atraviesa, que está aquí justo atrás de la comunidad, pero que está sumamente contaminado, donde la gente ni siquiera sabe cómo llegar a río porque está tan oculto entre toda la infraestructura. Entonces hemos iniciado con un proceso primero 
de reconectar, ¿verdad? A la comunidad con el río y luego, sí, hacer labores de limpieza y de ¿cómo se llama esto? Reforestación, etc., ¿no? Pero son procesos comunitarios que al final yo creo que el mayor impacto que causan es en la vida de cada persona que participa, en las relaciones que se forman con la gente, en los intereses comunes que se encuentran, ¿verdad? (Comunicación personal, Álvarez, 2019).

Una persona que pierde su comunidad comprende la necesidad de esta misma. ¿Cómo es posible que quienes cuiden de nuestros hijos e hijas costarricenses sean personas salvadoreñas? No se trata de quiénes son, al contrario, debemos estar eternamente agradecidos y agradecidas, se trata de lo que dice de nuestra sociedad costarricense. Sería lindo vivir en un mundo donde aprendemos desde el amor; pero, en definitiva, estamos viviendo en un mundo donde se acciona desde el temor y la individualidad. Esta solidaridad y este deseo de "crear comunidad" que aprendemos de este testimonio y de muchos otros son el tipo de modelos a seguir que debemos compartir y promover. Las personas refugiadas centroamericanas vienen de espacios donde muchas veces es imposible intentar gestionar proyectos de bienestar social sin arriesgar la vida. Ya sean las maras, las corporativas o los gobiernos mismos que atenten contra sus vidas, los grupos refugiados traen consigo una sabiduría incalculable para nuestra realidad costarricense. Este país que no vive la violencia del ejército, pero sí la educativa. Este país que se piensa valle centrista y olvida a sus compañeros y compañeras en las bananeras, las piñeras, en las comunidades indígenas, en las fronteras de lo que concebimos como "Costa Rica". Esta sociedad de "siervos menguados" debe decidir si el ser pacífico significa ser mediocre, o si debemos reivindicar nuestra esencia antes de que sea muy tarde. Antes de que aquí también se pueda reprimir a las personas que se tiren a la calle a demandar sus derechos con una policía que cada día más se parece a un ejército de soldados azul oscuro, las personas migrantes que vienen a Costa Rica ven aquí un país seguro, un país con oportunidades de educación, de trabajo, un país afortunado. ¿Cómo sería gestionar nuestra realidad costarricense desde este sentirnos afortunados y afortunadas?

Yo creo que eso es como todo un proceso, ¿verdad? Porque obviamente como te decía, el primer año era como, o sea, "iqué estamos haciendo aquí?" Y bueno, a muchas de las familias que hemos acompañado les ha pasado y hay quienes se han devuelto, a pesar de que saben que este es un riesgo para sus vidas y las de sus familias. Y creo que aquí lo importante es cómo perseverar y también tener la guía, ¿verdad? Tener la guía de personas que te orienten. Hacer la comunidad es muy importante.

Yo creo que, si yo me pongo a ver mi pasado, mi presente, mi futuro, estando aqui y estando en El Salvador... si yo posiblemente me hubiera quedado en El Salvador, nada de lo que estoy haciendo ahora lo estaría haciendo, ninguno de los aprendizajes que he 
tenido ahora los habría tenido, mucha gente que he conocido, que me ha hecho crecer como persona también no estaría, iverdad? Entonces, eso me hace como ver la parte positiva de este cambio, ¿no? Y también agradecer mucho, porque, o sea entré a la universidad con una beca que me dieron por el hecho de ser una persona refugiada. Estoy en una maestría con una beca que me dieron por el hecho de ser una persona refugiada, recientemente terminé un curso con la Universidad de Harvard, que me dieron, con una beca, por el hecho de ser una persona refugiada, ¿verdad? Entonces, yo te digo que agradecer por las oportunidades que me trajo y me sigue trayendo todo este proceso para crecer en el área intelectual y personal, porque por las áreas que me he ido de estudio, obviamente hay un pacto en la vida y en el entender, en el entender de todo tu entorno, ¿no? Que, si me hubiera quedado allá, iuy! O sea, no sé, creo que sería más triste, por seguir reproduciendo modelos, por seguir bajo lógicas capitalistas, que no se le puede culpar a la gente de estar así, porque, o sea, qué opciones hay, ¿verdad?

Pero sí, la cuestión es que sí, yo agradezco mucho a pesar de todo lo que se tuvo que sufrir, lo que se tuvo que vivir... las nuevas oportunidades que se me han dado al llegar aquí. Y eso es una cosa que a mí me duele mucho con los jóvenes que trabajamos, ¿verdad? Porque bueno ha habido casos de chicos que ya han terminado el colegio y les digo: "bueno vayan, empiecen, y hagan el examen de admisión y se meten a la universidad;" "ay no, es que las universidades públicas, mucha cuesta, mleh," y sí es difícil, ¿verdad? Pero son oportunidades que están ahí para ellos y no las toman, y a mí eso me da tanta tristeza.

En pocas palabras es como al final un sentido de agradecimiento por la experiencia vivida, porque eso también nos ha creado empatía para acompañar a otras familias... A otras personas, sí, porque sí hemos crecido mucho y bueno para mi hija también ha sido como una súper experiencia, porque como estamos en una comunidad internacional, pues ella ahora a sus ocho años es completamente bilingüe, tuvo la oportunidad de entrar al Conservatorio Castella donde se está formando en las artes de una manera maravillosa para mí. Y que son oportunidades que tampoco en nuestro país hubiera tenido, entonces yo también me siento muy agradecida por las oportunidades que se le abren a ella, así como las que se me han abierto a mí. (Comunicación personal, Álvarez, 2019)

Si te pudieras imaginar el cuerpo lleno de algo, ¿de qué sería?

Flores porque este también ha sido un proceso, que se me ha permitido hacer aquí, que es estar con la naturaleza, reconectar con el espacio, o con la experiencia de sembrar y reproducir, que es una cosa que para mí ha sido terapéutica también y que me ha servido también para formar comunidad con la gente a mi alrededor, todos los jueves nos reunimos a trabajar en nuestra huerta y sembrar semillas y a cosechar frutos, y en ese sembrar semillas, se siembran también amistades, se siembran risas, se siembran tristezas 
también, pero se comparten juntos al final los frutos, entonces para mí es muy valioso todo esto. (Comunicación personal, Álvarez, 2019)

\section{Referencias}

Bachelet, P. (2017). Crimen conlleva altos costos sociales, públicos y privados en América Latina y el Caribe: Estudio BID. https://www.iadb.org/es/noticias/comunicados-de-prensa/2017-02-03/cuanto-le-cuesta-el-crimen-a-america-latina\%2C11714.html

Barrios, M. A. (2016). Geopolítica de la seguridad: Crime organizado y globalización. https://www. alainet.org/es/articulo/181036

Calderon, L. (2017). "Tu eres recordar" La historia oral y el estudio del proceso migratorio contemporáneo. En Graciela De Garay y Jorge Aceves (Coords.), Entrevistar: ¿Para que? Múltiples escuchas desde diversos cuadrantes (pp. 271-297). México, Instituto Mora.

Casa Adobe. (s. f.). Living in community. Vivir en comunidad. http://casaadobe.org/wp/

Cuevas, R. (2012). De Banana Republics a Repúblicas Maquileras: La cultura en Centroamérica en tiempo de globalización neoliberal (1990-2010). Editorial UNED.

Dalby, C., \& Carranza, C. (2019) Balance de InSight Crime sobre los homicidios en 2018. https://es.insightcrime.org/noticias/analisis/balance-de-insight-crime-sobre-los-homicidios-en-2018/

Elbaum, J. (2018). La larga marcha del hambre: Éxodos del naufragio neoliberal. http://www. surysur.net/la-larga-marcha-del-hambre-exodos-del-naufragio-neoliberal/

Hayes, M. (2018). Gringolandia: Lifestyle Migration under Late Capitalism. University of Minnesota Press.

Perrozompopo. (2015). Migración, amor y poder de cambio. TEDx Pura Vida Joven. https:// www.youtube.com/watch?v=ZgBiENaxF8A

Perrozompopo. (2011). Mirando al Sur. Letra. https://www.letras.com/perrozompopo/1906054/

Poveda, C. (2009). La vida loca: Las maras propagan el terror por las calles de El Salvador. https://www.documaniatv.com/social/la-vida-loca-mara-la-18-video_638a4083f.html

Rojas, F. (2008). Globalización y violencia en América Latina: Debilidad estatal, inequidad y crimen organizado inhiben el desarrollo humano.

Segato, R. (2018). La violencia contra las mujeres es sobre las mujeres contra la vida. Diálogo con Rita Segato. Fundación Rosa Luxemburgo. http://www.biodiversidadla.org/Documentos/ La_violencia_contra_las_mujeres_es_sobre_las_mujeres_contra_la_vida._Dialogo_con_Rita_Segato 
Tica Bus. (s. f.). Rutas San Salvador a San José. https://www.ticabus.com/

Valencia, R. (2018) El Salvador repetirá en 2018 como el país más homicida del Triángulo Norte. https:/elfaro.net/es/201812/el_salvador/22750/El-Salvador-repetir\%C3\%A1-en-2018-como-el-pa\%C3\%ADs-m\%C3\%A1s-homicida-del-Tri\%C3\%A1ngulo-Norte.htm 